\title{
INCIDENCE OF MONGOLISM AND ITS DIAGNOSIS IN THE NEWBORN
}

\author{
BY \\ CEDRIC CARTER* \\ Department of Morbid Anatomy, The Hospital for Sick Children, \\ Great Ormond Street, London \\ and \\ DERMOD MACCARTHY \\ Late Assistant to the Professor of Child Health, University of London
}

An accurate estimate of the incidence in the general population of mongolism at birth is required for the genetic study of the disease. Penrose (1949) has estimated the frequency of the condition among children of school age in Great Britain from the records of local authorities; the incidence among children aged 10 to 14 is probably about 1 in 2,000 . He stresses, however, that the high infant mortality of mongols implies that the incidence at birth is considerably higher than this.

The only figure available for the incidence at birth in Great Britain is that given by Malpas (1937) for a maternity hospital; he found eighteen cases in 13,964 births, that is 1 in 776; but with such small numbers the random error may be large and mothers who have their babies in hospital are to some extent selected. For the U.S.A., too, the only figures available are based on the experience of single maternity units (Jenkins, 1933; Parker, 1950).

The only factor known to be related to the incidence of mongolism is the mother's age, the apparent relation between birth order and mongolism being due to the association of maternal age and birth order (Penrose, 1933). So that while it is difficult to get any direct estimate of the incidence of mongolism at birth in the general population, it is probably correct to apply figures obtained from hospital births provided that due correction is made for the fact that mothers in hospital are rather younger than mothers having their confinements at home.

\section{INCIDENCE IN HoSPITAL BIRTHS}

With the help of the National Birthday Trust Fund a circular was sent in the summer of 1949 to fourteen maternity units and maternity hospitals in London and the Home Counties, asking for the number of mongols born in the last few years and also the total number of births (live and stillborn). All the hospitals

* In receipt of a grant from the National Birthday Trust Fund. 
interpreted our ambiguous term " births" as mothers giving birth to children (maternities) rather than as children born, but the figures are readily convertible since about 81 children are born in eighty maternities. Two of the hospitals had no reliable record of the number of mongols born.

TABLE I

Incidence of Mongolism Related to Maternal Age

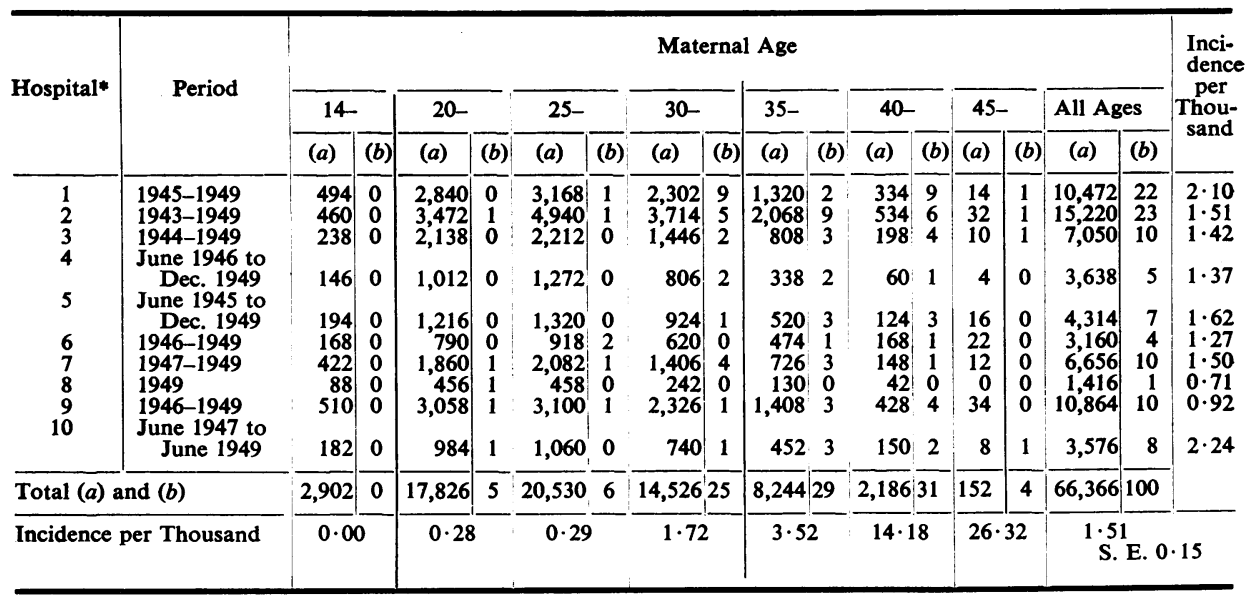

(a) Number of related maternities (obtained by doubling the observed numbers, since ages were recorded for only half the mothers entered in the register).

(b) Number of mongols.

* The hospitals taking part in this inquiry were, in alphabetical order:

The hospitals taking part in this inquiry were, in alphabetical order:
North Middlesex Hospital

General Lying-in Hospital

Guy's Hospital

Hammersmith Hospital

British Hospital for Mothers and Babies

Middlesex Hospital

Queen Charlotte's Maternity Hospital

Salvation Army Mothers' Hospital

St. Helier Hospital

Thorpe Coombe Maternity Hospital

University College Hospital

West Middlesex Hospital

The figures supplied by the remaining twelve hospitals were consistent in that the differences in the incidence of mongolism were all within the bounds of random variation. It is probable, however, that diagnosis was relatively more complete in some hospitals than in others. This is suggested by the relatively high incidence recorded for one hospital (No. 1 of Table I), where one of us (D.M.) has taken a special interest in mongolism, and for another (No. 5 of Table I) where the obstetrician keeps in close touch with the Public Health Department and all mongols are followed up till death or certification as mentally defective.

In 1950 the hospitals were asked to supply the age of the mother at the birth of the mongol, and one of us (C.C.) visited ten of the twelve hospitals; the other two hospitals were excluded because it was not convenient to visit them, but they had had a normal incidence of mongolism ( 2 in 2,400, and 5 in 2,755 maternities respectively). At this visit the ages of half the mothers were recorded for the periods for which this information was conveniently tabulated in the maternity register book. In one hospital (No. 8), age had only been tabulated since January, 1949. The half sample of mothers were those on alternate pages of the register 
book. At this visit the survey was carried forward in several hospitals (Nos. 4, 5, 6,7 , and 8) to the end of 1949 where the 1949 inquiry had terminated in June 1949, and it was also carried back a year or two in three hospitals (Nos. 1, 2, 3) where help was available in classifying the mothers' ages. At the same time the grounds for the diagnosis of mongolism given in the records of the mongol children were noted. The figures thus obtained are shown in Table I.

In all 100 mongols were born in 66,366 maternities, an incidence of 1.51 $( \pm 0 \cdot 15)$ per thousand, or 1 in 660 maternities (the range within twice the standard error being from about 1 in 830 to 1 in 550). If the two hospitals not visited are included, there were 107 mongols in 71,521 maternities, an incidence of 1.5 per thousand. In so far as mongols remain undiagnosed in infancy more often than normal babies are wrongly called mongols, this estimate will be too low.

The increase of the incidence of mongolism with increasing maternal age is striking. The incidence of over 2.5 per cent. for mothers over 45 is based on numbers too small to be reliable, but is nevertheless consistent with the general trend of the increase with maternal age. These age-specific incidences, obtained by direct comparison, agree with the indirect estimates of Penrose (1949a).

\section{InCidence in the General Population}

The age-specific rates shown in Table I may be applied to any population for which the age distribution classified in the same groups is available. In Table II they have been applied to all maternities in Greater London, and to all maternities in England and Wales, for 1947 (in both cases excluding those in which maternal age is not stated); the figures are taken from the Registrar-General's Statistical Review of England and Wales (1947).

TABLE II

Age Distribution of Maternities (eXCluding those for Which age IS NOT STATED) IN Greater LONDON, AND ENGLAND AND WALES FOR 1947, WITH THE EXPECTED NuMBER OF MONGOLS BORN IN EACH AGE Group

\begin{tabular}{|c|c|c|c|c|c|c|c|c|c|c|}
\hline \multirow{2}{*}{\multicolumn{2}{|c|}{ Area }} & \multicolumn{8}{|c|}{ Maternal Age } & \multirow{2}{*}{$\begin{array}{c}\text { Incidence } \\
\text { per } \\
\text { Thousand }\end{array}$} \\
\hline & & \multirow{2}{*}{$\frac{\text { Under } 20}{4,834}$} & \multirow{2}{*}{$\frac{20}{40,525}$} & \multirow{2}{*}{$\frac{25-}{53,590}$} & \multirow{2}{*}{$\frac{30-}{40,357}$} & \multirow{2}{*}{$\frac{35-}{23,273}$} & \multirow{2}{*}{$\begin{array}{l}40- \\
6,172 \\
\end{array}$} & \multirow{2}{*}{$\frac{45-}{373}$} & \multirow{2}{*}{$\frac{\text { All Ages }}{169,614}$} & \\
\hline Greater & Maternities & & & & & & & & & \multirow[b]{2}{*}{$1 \cdot 63$} \\
\hline & $\begin{array}{c}\text { Mongols } \\
\text { expected }\end{array}$ & 0.0 & $11 \cdot 4$ & $15 \cdot 6$ & $69 \cdot 4$ & $81 \cdot 9$ & $87 \cdot 5$ & $9 \cdot 8$ & 276 & \\
\hline \multirow{2}{*}{$\begin{array}{l}\text { England } \\
\text { and Wales }\end{array}$} & Maternities & 28,051 & 228,953 & 282,705 & 196,663 & 115,881 & 33,450 & 2,347 & 891,504 & \multirow[b]{2}{*}{$1 \cdot 60$} \\
\hline & $\begin{array}{l}\text { Mongols } \\
\text { expected }\end{array}$ & 0.0 & $64 \cdot 2$ & $82 \cdot 1$ & $338 \cdot 5$ & $407 \cdot 7$ & $474 \cdot 2$ & $61 \cdot 8$ & 1,428 & \\
\hline
\end{tabular}

Both for Greater London and for England and Wales mothers having children in 1947 were rather older than the hospital population as a whole, so that the estimated incidence of mongolism is higher. For Greater London it was 1.63 per thousand and for England and Wales 1.6 per thousand maternities. Here again the true incidence will be higher still in so far as mongols are not always recognized in infancy. 


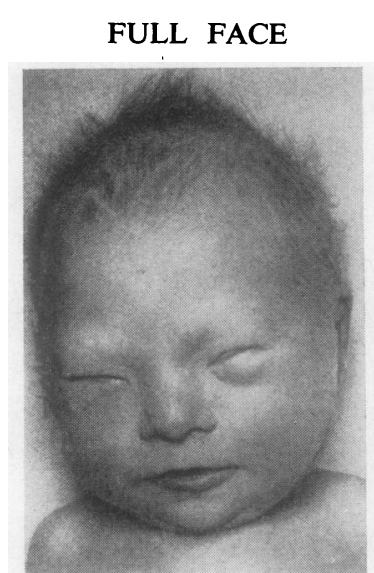

(i)

Infant G.

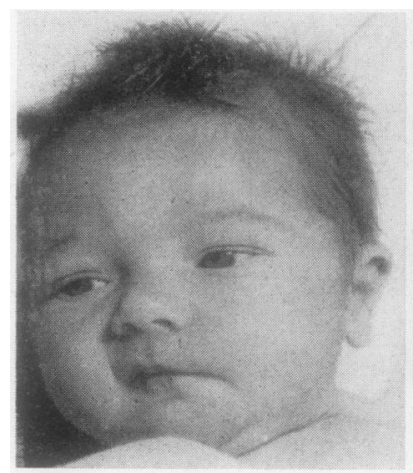

(i)

Normal Boy

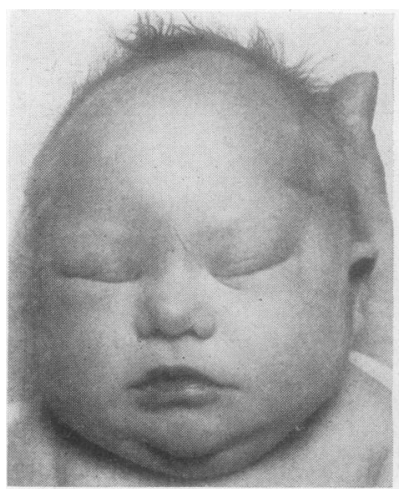

(i)

Infant $P$ TONGUE

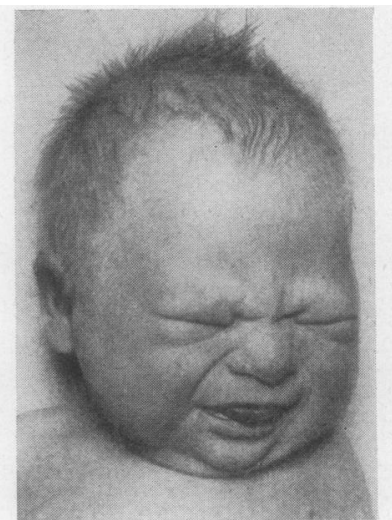

(ii)

Infant G.

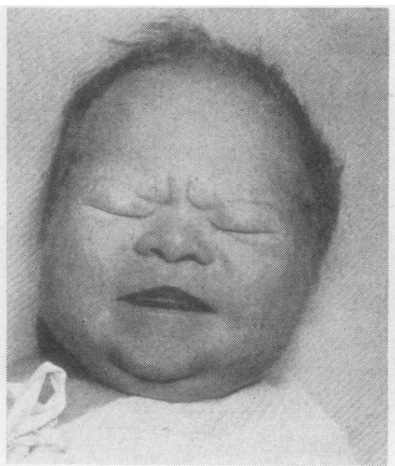

(ii)

Infant $\mathbf{R}$.

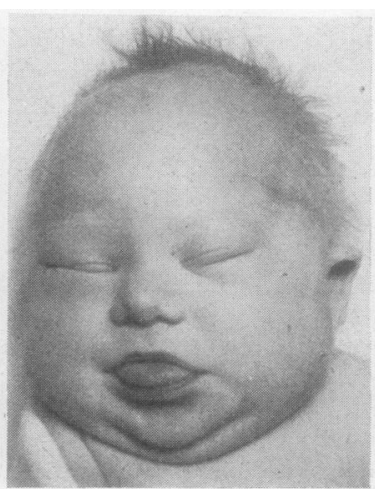

(ii)

Infant $\mathbf{P}$.
PROFILE or HALF PROFILE

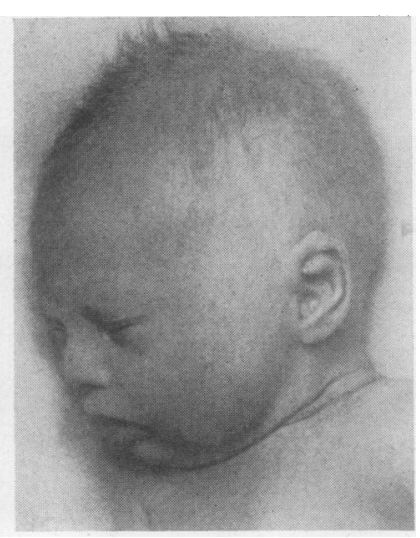

(iii)

Infant $\mathrm{G}$.

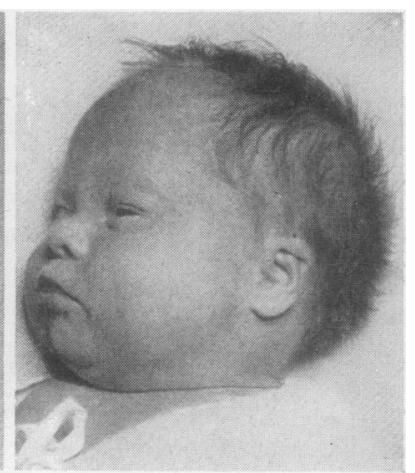

(iii)

Infant $\mathbf{R}$.

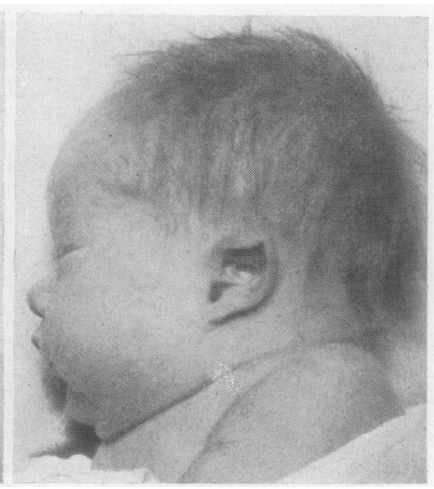

(iii)

Infant $\mathbf{P}$. 
INCIDENCE OF MONGOLISM AND DIAGNOSIS IN NEWBORN

FULL FACE

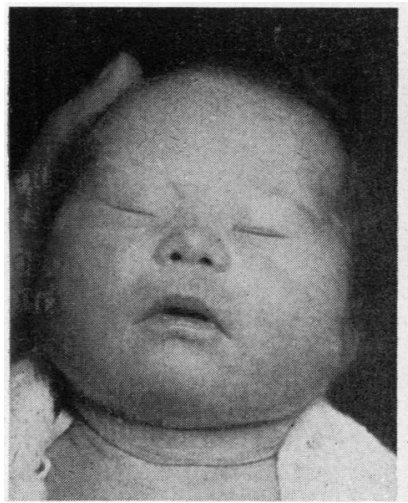

(i)

Infant $\mathbf{M}$.

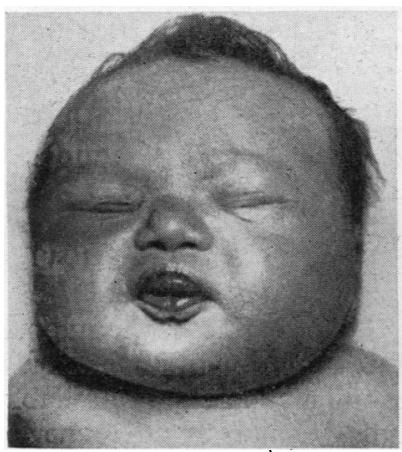

(i)

Infant $\mathbf{H}$.

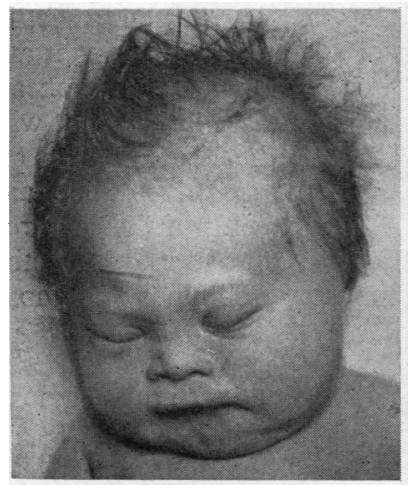

(i)

Infant $\mathrm{L}$.
TONGUE

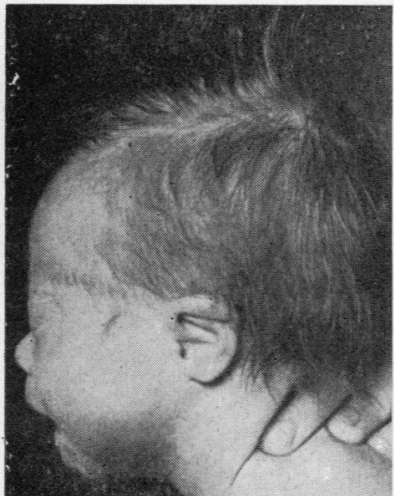

(ii)

Infant $\mathbf{M}$.

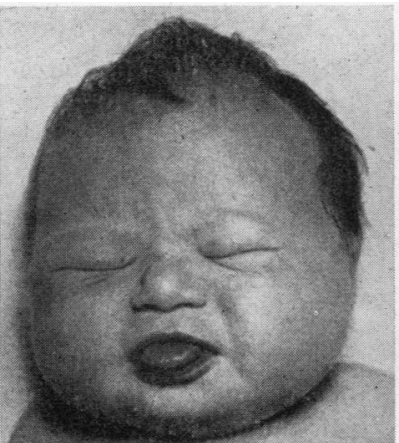

(ii)

Infant $\mathbf{H}$.

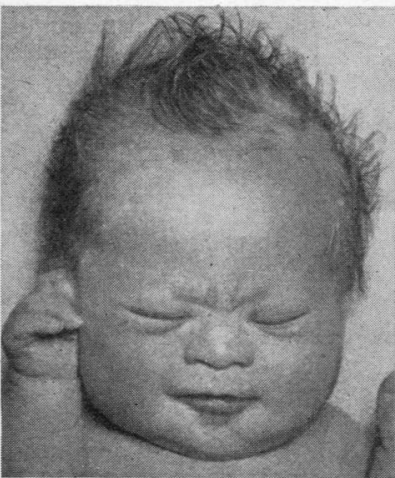

(ii) PROFILE or HALF PROFILE

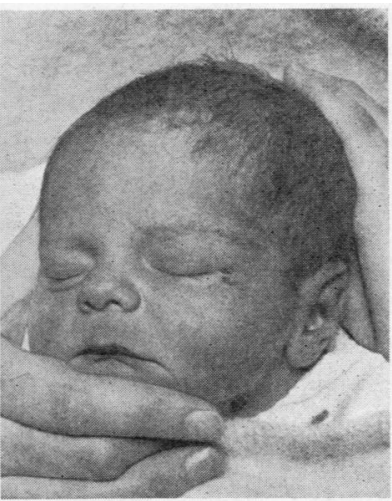

(iii)

Normal Boy

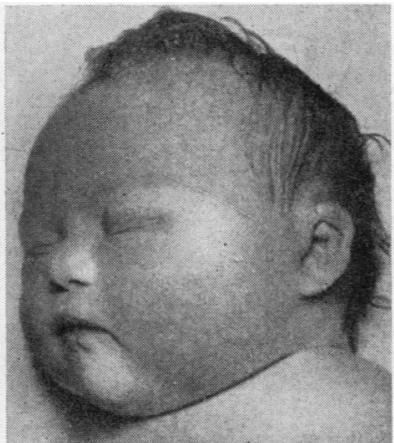

(iii)

Infant $\mathrm{H}$.

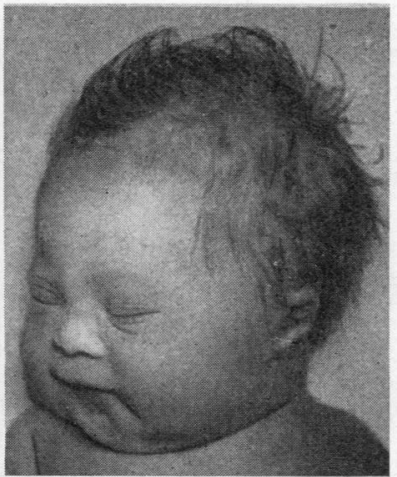

(iii)

Infant $\mathrm{L}$. 
The incidence of about 3 in 2,000 at birth, when compared with Penrose's finding of an incidence of about 1 in 2,000 among schoolchildren 10 to 14 years old, implies that two mongols out of three die in the first ten years of life.

\section{Diagnosis of Mongolism in the Newly Born}

The accuracy of any estimate of the incidence of mongolism depends, of course, on the completeness with which the disease is recognized. It is probably true to say that, in maternity hospitals at any rate, the first to draw attention to the abnormality of the infant is the midwife. Confirmation or refutation then follows after examination by a doctor, who may or may not appeal to another authority before committing himself. Except, therefore, when a routine medical inspection of all newborn infants is made by a paediatrician, obstetrician, or house officer, the preliminary selection of possible mongols is made by the nursing staff. Once familiar with the features (as experienced midwives usually are) they can be relied upon to do this, for the picture, though difficult to analyse or describe, is almost as easy to recognize in the newborn as it is in older children. The important thing is that all concerned with the care of newborn infants should have an opportunity of studying cases that occur and be stimulated to look out for it. The illustrations on pp. 86 and 87, and the following description, are given in support of our contention that in the majority of cases the diagnosis can be made with confidence and without hesitation.

(1) General Impression.-The diagnosis of mongolism is made (Penrose, 1949b): " by deliberately or unwittingly adding up the points in its favour".

Many of these points are recognizable simultaneously at a glance and it is the summation of their effect or their absence that is responsible for the immediate impression"a mongol" or "not a mongol". To anyone with experience this first impression is reliable. Conviction is apt to weaken whilst examining the child feature by feature, but is renewed when the child is once more viewed as a whole, especially after letting the eye dwell for a little while on one or more normal infants.

The face of the mongol is plain, expressionless, uninteresting, with coarse, insignificant, poorly-fashioned features. By contrast the normal infant has an air of intelligence, he looks distinguished, and his features convey the impression of a capacity for thought and subtle emotional expression which is completely lacking in the mongol. His forehead, orbits, nose, lips, and ears are finely moulded. These features are also larger and, with the exception of the eyes, more widely spaced, giving importance to the face; whereas the mongol facies presents nothing but a large expanse on which the smaller, duller, and much less delicate features are grouped nearer the centre. The spacing of the features, however, though easily ascertained by inspection, is difficult to measure. Subjective impressions such as these undoubtedly play a part in making the preliminary diagnosis and therefore seem to be worth consideration.

(2) Separate Features. - The following appear to us to be reliable guides to the diagnosis of mongolism in the newborn:

Head.-The shape is rounder than in the normal infant and the occiput less prominent. The cephalic index is increased (though the moulding often present in the newborn makes its actual measurement unreliable). The posterior fontanelle may be patent, but a more 
constant feature is a slight bony deficiency at the suture line just above the lamda; this is sometimes known as the third fontanelle.

Eyes.-There is an oblique slant of the palpebral fissure (probably the most reliable single feature). The epicanthic fold is not invariably present. The length of the palpebral fissure is small. Blepharitis is not seen in the newborn.

Nose.-This is broader, flatter, and simpler than the normal.

Mouth.-The corners are frequently turned downwards, giving a sulky, bitter expression, both in crying and at rest. The grimaces so characteristic of the older mongol child are already seen at this age.

Tongue.-This is frequently protruded, and exhibits " trombone" movements.

Ears.-These are smaller and squarer than the normal, and knotty, or crudely formed.

Hands.-The fingers are short and stumpy. The little finger shows the characteristic incurving with a short second phalanx. The thumb arises lower down on the palm and the whole appearance lacks the delicacy of the normal infant's hand with its long tapering fingers. A single transverse palmar crease is frequently present on one hand if not on both. The dermal ridges which are a most useful guide in the older infant are extremely difficult to see or to measure at this age, but characteristic alterations are detectable in some cases with suitable technique.

Feet.-A wide cleft between big toe and first toe, though often present, is an unreliable sign, being difficult to distinguish from the appearances in normal infants.

Laxity of Ligaments.-A puppy-like floppiness is often quite clearly detectable on handling the infant when quiet, and laxity of the ligaments allows rather more unfolding of the foetal position to be performed than in the normal infant. Divarication of the recti may be present.

Length.-This is stated to be normal at birth by Benda (1939), though short stature is an important feature in older mongols.

(3) Coincident Congenital Abnormalities.-It must be remembered that although congenital heart lesions are frequently found in mongols, the characteristic murmurs by which they can be detected are often not audible at this age.

(4) Negative Ponsts.-Characteristics of the skin, hair, mucous membranes, and iris seen in older children cannot be clearly defined in the newborn mongol, and the fissured tongue is not seen.

\section{SUMMARY}

(1) Twelve maternity hospitals and maternity units in London and the Home Counties provided figures of the numbers of mongols born over the past few years. The total incidence was 107 in 71,521 maternities; that is, 1.5 per thousand, or 1 in every 666 mothers giving birth to live or stillborn children. Since the condition is more often missed than wrongly diagnosed it is probable that the true incidence in hospital births is rather higher than this.

(2) The age distribution of half the mothers and also that of all the mothers of mongols in ten of these hospitals was ascertained; from this the incidence of mongolism to mothers in five-year age groups was calculated. The incidence in mothers under 25 is very low, but in mothers over 40 it is more than 1 per cent. To arrive at an estimate of the incidence of mongolism in the general population, these age-specific incidences were then applied to the Registrar-General's figures for all maternities, classified by age, in Greater London and in England and Wales 
for 1947. These populations are older than the hospital mothers, so that the estimated incidence of mongolism is higher, about 1.6 per thousand, or 1 in 620 maternities; the true incidence will be higher still in so far as all mongols are not diagnosed in infancy.

(3) The features of mongolism in the newborn are described and the grounds for the diagnosis of mongolism are discussed.

We wish to thank the obstetric and paediatric staffs of the hospitals for supplying the information given in Table I, and for giving us access to their records of the ages of their mothers. We are greatly indebted to Miss D. V. Riddick of the National Birthday Trust Fund for her help in organizing the inquiry. Professor Penrose kindly supplied part of the age distribution of the mothers at University College Hospital.

\section{REFERENCES}

Benda, C. E. (1939). Arch. Neurol. Psychiat. Chicago, 41, 83.

Jenkins, R. L. (1933). Amer. J. Dis. Child., 45, 506.

Malpas, P. (1937). J. Obstet. Gynaec. Brit. Emp., 44, 434.

Parker, G. F. (1950). J. Pediat., 36, 493.

Penrose, L. S. (1933). J. Genet., 27, 219.

(1949). J. ment. Sci., 95, 685 .

- (1949a). "The Biology of Mental Defect", p. 186. Sidgwick and Jackson, London. (1949b). Ibid., p. 185. 